\title{
NATURAL SCIENCE AND TECHNOLOGY EDUCATION: VALUES COMPONENT
}

\author{
Vincentas Lamanauskas \\ Šiauliai University, Lithuania
}

\begin{abstract}
One cannot doubt in the importance of Natural science and Technology education. Over the last two or three decades, attention to Natural science and Technology education has been significantly growing. On the one hand, science and technology development was encouraging this, on the other hand, one can observe a decreasing young generation interest in natural sciences and technologies. Paradoxical contrast - in technologically developed countries youth interest in natural sciences is significantly decreased. Completely different situation is in so-called developing countries. About such a situation a lot has been written, discussed, plenty of scientific research have been carried out and so on. It is obvious, that such a situation is determined by a great number of factors. However, in spite of this, education system has to change, to search for effective natural science and technology education forms and methods. The most important goal is suitable and adequate natural science and technology education of the young generation. However, what does suitable and adequate mean? What is suitability and adequacy content? Is it only quantitatively and qualitatively new knowledge and abilities? Conception, oriented only to pragmatics (only to knowledge, qualifications and/or competencies) in a certain sense is faulty. After all, some kind of competition goes, creating various education strategies and technologies. In other words, we are as if "lost" in the labyrinths of various theories, approaches, positions and attitudes and so on (Lamanauskas, 2015). A certain "resetting" is
\end{abstract} necessary, an audit of the current condition, an outline of perspective education development trends.

In recent years, both in Lithuania and in other countries, natural science and technology development is given emphasis to. Decreasing youth interest in natural sciences and/or technology has become a big concern. On the one hand, such concern is reasonable, because youth motivation choosing the studies at universities is usually directed to social and humanitarian sciences. E.g., in Lithuania, almost $50 \%$ of students choose the studies in social-humanitarian science field. Such a situation is determined by a number of reasons. To study natural sciences and technology is complicated enough, the studies are time consuming, require big efforts and so on. One can notice, how in many world countries it is sought to popularise natural sciences in academic society, in schools and gymnasiums, to encourage pupils to choose natural science and technology studies. Western attitude is obviously practical. It is emphasised, that important are only technical sciences, such as physics, chemistry, cybernetics, biology, nanotechnologies and so on. Social-humanitarian sphere is quite often "pushed" aside. Earlier man used to feel inseparable from nature. Such dependency reflected through his way of life, customs, traditions, rituals, creation and so on. So-called present-day (civilised) man fell out of a habit to relate himself with everything what is alive, quite often the feeling of harmony, unity with nature and with the surrounding environment is alien for such a man. Constantly we hear information and/or read the news about endangered natural nature, devastated environment, global climate change and so on. Society more and more becomes pragmatic. Everything has to give benefit, profit and so on. What is more, according to prediction, after 2030-2040 we will enter the century of biotechnologies. Traditionally, science was characterised as value-free. However, as the researchers notice, the common characterization of science as value-free or value-neutral can be misleading, for example, scientists strongly disvalue fraud and error (Alchin, 1999). Besides, values directly condition and determine our behaviour. Earlier mentioned decreased youth interest in natural sciences and technologies is also related to values. According to A. Bishop (2008) in mathematics and science education values are crucial components of classrooms' affective environments, and thus have a crucial influence on the ways students choose to engage (or not engage) with mathematics and science. 
Looking through various political documents, or following public discourse one can notice, that the necessity to educate not only pupils' but first of all teachers' initiative, enterprising and abilities to generate new ideas in the sphere of natural sciences, technologies, engineering and mathematics is constantly encouraged. I would like to draw attention to the fact, that it is not spoken or very little spoken about value component of natural science and technology education. Quite often education is directed towards the education of a typical consumer, a man who is not able to work well, is accustomed and is trained to get everything quickly, here and now, with minimal efforts, however taught to turn any truth (or axiom) or even world law into a simple personal opinion. As if everything depended only on man's attitude, opinion, position. One can say, that typical $20^{\text {th }}$ century natural science positivism comes back, in the centre of which is an almighty man. However, what do we observe? We observe the planet Earth, more and more torn by nature elements and increasing pollution. So, value component of natural science and technology education should become a priority in all education system, at all its levels. Values should be systematically inoculated, directing young people to become mature personalities. This means the ability to apply the acquired knowledge and abilities practically, to solve everyday life problems, to educate self-confidence, feel responsibility and be able to adapt to the changing environment and seek to save the environment, suitable for the man's existence. Values are formed not adapting to the situation "here and now", but orienting to future perspective "there and then". Value component of natural science and technology education should occupy a proper place in educational practice, and should be more exhaustively examined in a scientific sense. The most important value of such position is - a man is not and cannot be only nature consumer. He is responsible for the environment change and its conservation. It is understandable, that various value systems exist, which are based on various criteria. After all, values also constantly change. However, new values sometimes quite paradoxically entwine with the traditional ones, and in this ceaseless value change a certain their stability is also seen, a certain value "kernel", which consolidates all the other values, gives essence to them (Kani auskas, 2014). So, value component of natural science and technology education is and will remain one of the most important in an increasingly science and technology-based world.

\section{References}

Alchin, D. (1999). Values in science: An educational perspective. Science \& Education, 8, 1-12.

Bishop, A. (2008). Values in mathematics and science education: Similarities and differences. The Montana Mathematics Enthusiast, 5 (1), 47-58

Kanišauskas, S. (2014). Vertybiu erdvèlaikis: kaitos ir pastovumo problema [Values space-time: The problem of changing and stability]. Filosofija. Sociologija / Philosophy. Sociology, 25 (3), 164-173.

Lamanauskas, V. (2015). Natural science and technology education: "Resetting" meaning. In.: Lamanauskas V., Šlekienè V., Ragulienè L. (Eds.), State-of-the-art and future perspectives. Proceedings of the $1^{\text {st }}$ International Baltic Symposium on Science and Technology Education (BalticSTE2015). iauliai: Scientia Socialis Press, p. 7-10.

Received: October 25, 2015

Accepted: December 15, 2015

Vincentas Lamanauskas

PhD., Professor, Natural Science Education Research Centre, University of

Siauliai, 25-119 P. Višinskio Street, LT- 76351, Siauliai, Lithuania.

E-mail: lamanauskas@lamanauskas.puslapiai.It

Website: http://www.lamanauskas.puslapiai.lt 